\title{
Formation potentials of typical disinfection byproducts and changes of genotoxicity for chlorinated tertiary effluent pretreated by ozone
}

\author{
CAO Nan ${ }^{1}$, MIAO Tingting ${ }^{1,2}$, LI Kuixiao ${ }^{1}$, ZHANG Yu$^{1}$, YANG Min ${ }^{1, *}$ \\ 1. State Key Laboratory of Environmental Aquatic Chemistry, Research Center for Eco-Environmental Sciences, Chinese Academy of Sciences, \\ Beijing 100085, China. E-mail: yangmin@rcees.ac.cn \\ 2. Material Science and Technology Institute, Beijing Forestry University, Beijing 100083, China
}

Received 12 May 2008; revised 06 June 2008; accepted 16 June 2008

\begin{abstract}
The effects of ozonation on the formation potential of typical disinfection byproducts (DBPs) and the changes of genotoxicity during post chlorination of tertiary effluent from a sewage treatment plant were investigated. Ozonation enhanced the yields of all detected chlorine DBPs except $\mathrm{CHCl}_{3}$. At a chlorine dose of $5 \mathrm{mg} / \mathrm{L}$, the three brominated THMs and five HAAs increased, while chloroform decreased with the increase of ozone dose from 0 to $10 \mathrm{mg} / \mathrm{L}$ (ozone dose in consumption base). At a chlorine dose of $10 \mathrm{mg} / \mathrm{L}$, the two mixed bromochloro species THMs and two dominant HAAs (DCAA and TCAA) increased firstly and then decreased with the increase of ozone dose, with the turning point approximately occurring at an ozone dose of $5 \mathrm{mg} / \mathrm{L}$. The genotoxicity detected using umu test, on the other hand, was removed from $7 \mu \mathrm{g} 4-\mathrm{NQO} / \mathrm{L}$ to a negligible level by ozonation under an ozone dose of $5 \mathrm{mg} / \mathrm{L}$. Chlorination could further remove the genotoxicity to some extent. It was found that SUVA (UV absorbance divided by DOC concentration) might be used as an indicative parameter for monitoring the removal of genotoxicity during the oxidation.
\end{abstract}

Key words: wastewater reclamation; ozonation; chlorination; disinfection byproducts; genotoxicity

DOI: $10.1016 /$ S1001-0742(08)62284-6

\section{Introduction}

With the increasing demand of water resource, reclamation and reuse of municipal wastewater is becoming more and more attractive. Recently, there is an increasing interest in adopting ozone in wastewater reclamation treatment to upgrade effluents for the purposes of decolorization, removal of odor and decomposition of micropollutants (Takahara et al., 2006). Although ozone acts as an effective disinfectant, post chlorination is generally required to control microbial re-growth in distribution systems since ozone cannot produce a persistent disinfectant residual (Singer, 1994). In China, it is required that the total residual chlorine should not be less than $0.2 \mathrm{mg} / \mathrm{L}$ in the distribution terminals.

Tertiary treatment including the combination of coagulation and sand filtration is usually adopted for the reclamation of the secondary effluent from municipal wastewater. The tertiary effluent, however, still contains high concentration of organic compounds, which could act as precursors of chlorine disinfection byproducts (DBPs). Formation and release of DBPs during water treatment has long been a big concern because of their harmful effects on human health. Ozonation was applied in some waterworks to remove the chlorinated DBP precursors as a

\footnotetext{
* Corresponding author. E-mail: yangmin@ rcees.ac.cn
}

pretreatment method (Nissinen et al., 2002). The decreases of THM and THAA formation during free chlorination of pre-ozonated water were observed (Chang et al., 2002, Guay et al., 2005). Although ozonation could change the structures of organic compounds in wastewater effluents, and even reduce the contents of organics, the effects of ozonation on the formation of DBPs and the toxicity of the reclaimed wastewater have not been well understood.

The aim of this study was to investigate the effect of ozonation on the formation of typical DBPs, as well as genotoxic potential in the following chlorination stage. The application of umu test was used to monitor the changes of the genotoxic potential.

\section{Materials and methods}

\subsection{Sampling collection and characterization}

The effluent used in this work was obtained from a reclamation plant in Beijing, which adopts a tertiary treatment including coagulation, sediment and sand filtration after traditional activated sludge treatment. One hundred liter tertiary effluent was taken directly from the reclamation system before chlorine disinfection, transferred to the laboratory and kept at $4^{\circ} \mathrm{C}$ for further treatments and analyses.

DOC, $\mathrm{UV}_{254}$ and bromide were measured with a TOC 
analyzer (Phoenix 8000, Tekmar-Dohrmann, USA), a UV3100 (Hitachi, Japan) and an ionic chromatograph (Dionex ICS1500, USA), respectively. $\mathrm{COD}_{\mathrm{Mn}}$ and ammonia nitrogen $\left(\mathrm{NH}_{3}-\mathrm{N}\right)$ were determined according to the Standard Methods of Water and Wastewater Monitoring of China. Free chlorine and total chlorine were measured using "Hach Colorimeter TMII for chlorin" (Hach, USA).

The major physico-chemical properties of the tertiary effluent are as follows: $\mathrm{pH} 7.2 \mathrm{1}$; $\mathrm{COD}_{\mathrm{Mn}} 9.1 \mathrm{mg} / \mathrm{L}$; DOC $6.7 \mathrm{mg} / \mathrm{L} ; \mathrm{UV}_{254} 11.7 \mathrm{~m}^{-1} ; \mathrm{NH}_{3}-\mathrm{N} 0.6 \mathrm{mg} / \mathrm{L} ; \mathrm{Br}^{-} 0.7$ $\mathrm{mg} / \mathrm{L} ; \mathrm{SS} 5 \mathrm{mg} / \mathrm{L}$.

\subsection{Ozonation and chlorination experiments}

Batch ozonation experiment was conducted in a glass column $(\varnothing 60 \mathrm{~mm} \times 1.5 \mathrm{~m})$ as shown in Fig. 1. The inlet and outlet ozone concentrations were monitored by a UV ozone monitor (Hare EG-600, Ebara Jitsugyo, Japan). Ozone gas was introduced into the reactor through a gas diffuser from the bottom after the reactor was full with the tertiary effluent. Ozone dose in consumption base $\left(C_{\mathrm{C}}\right)$ was calculated according to Eq. (1)

$C_{\mathrm{C}}=\frac{\left(C_{\mathrm{I}}-C_{\mathrm{O}}\right) \times F \times T}{V_{\mathrm{W}}}$

where, $C_{\mathrm{I}}(\mathrm{mg} / \mathrm{L})$ is inlet ozone concentration; $C_{\mathrm{O}}(\mathrm{mg} / \mathrm{L})$ is outlet ozone concentration; $F(\mathrm{~L} / \mathrm{min})$ is gas flowrate, $T$ (min) is reaction time, and $V_{\mathrm{W}}(\mathrm{L})$ is volume of water samples.

For chlorination, a given volume of stock chlorine solution (free chlorine concentration $60 \mathrm{~g} / \mathrm{L}$ ) was added to $1.2 \mathrm{~L}$ water samples treated with different ozone doses, following the addition of $20 \mathrm{~mL}$ buffer solutions $(0.25$ $\mathrm{mol} / \mathrm{L} \mathrm{KH}_{2} \mathrm{PO}_{4}$ and $0.25 \mathrm{~mol} / \mathrm{L} \mathrm{Na}_{2} \mathrm{HPO}_{4}$ ). After slowly shaking for $1 \mathrm{~h}$, the samples were stored headspace-free at ambient temperature in the dark for $72 \mathrm{~h}$. A $0.025-\mathrm{mol} / \mathrm{L}$ sodium sulfite was then added to the solution to eliminate residual chlorine.

\subsection{Chlorination DBPs analysis}

Four trihalomethanes (THMs), i.e., chloroform $\left(\mathrm{CHCl}_{3}\right)$, bromodichloromethane $\left(\mathrm{CHCl}_{2} \mathrm{Br}\right)$, dibromochloromethane $\left(\mathrm{CHClBr}_{2}\right)$ and bromoform $\left(\mathrm{CHBr}_{3}\right)$ were analyzed on a gas chromatograph $(6890 \mathrm{~N}$, Agilent, USA)

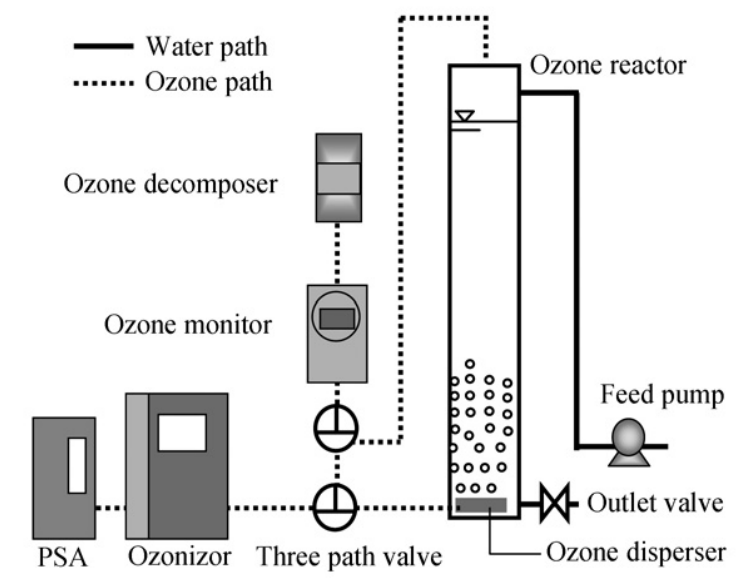

Fig. 1 Schematic diagram of experimental system. equipped with an HP-5 fused silica capillary column $(0.25 \mathrm{~mm} \times 30 \mathrm{~m})$ and an electron capture detector (ECD) following liquid/liquid extraction with hexane (HPLC grade, Fisher Chemicals, USA), in accordance with USEPA Method 551.1 (USEPA, 1995). Five haloacetic acids (HAAs), i.e., monochloroacetic acid (MCAA), monobromoacetic acid (MBAA), dichloroacetic acid (DCAA), dibromoroacetic acid (DBAA) and trichloroacetic acid (TCAA), were analyzed on the gas chromatograph using 1,2-dibromopropane as the internal standard, following liquid/liquid extraction with methyl$t$-butyl-ether (MTBE, HPLC grade, Fisher Chemicals, USA) and derivatization with acidic methanol (HPLC grade, Fisher Chemicals, USA) according to USEPA Method 552.3 (USEPA, 2003).

The analytical standards for HAAs were purchased from Acros Organics (Belgium), and THMs and internal standards were obtained from Accustandard Inc. (USA).

\subsection{Genotoxicity test}

Water samples for genotoxicity tests were filtered through GF/C membranes (Whatman, UK) without $\mathrm{pH}$ adjustment, and then passed through Oasis HLB solid extraction cartridges (6 mL $500 \mathrm{mg}$, Waters, USA). The cartridges had been conditioned beforehand with $10 \mathrm{~mL}$ of methanol (HPLC grade, Fisher Chemicals, USA) and 10 $\mathrm{mL}$ of distilled water. One liter of each sample was loaded to one cartridge, then dried under a nitrogen flow and eluted with $6 \mathrm{~mL}$ of methanol. The eluate was then dried under nitrogen flow. The dried residues were reconstituted with $100 \mu \mathrm{L}$ dimethylsulfoxide (DMSO, Ameresco, USA) and stored in the dark at $-20^{\circ} \mathrm{C}$ before use.

The genotoxicity was determined with the SOS/Umu bioassay (ISO 13829, 2000) using Salmonella typhimurium strain TA 1535/pSK1002. The test strain was provided by the Osaka Prefectural Institute of Public Health, Japan. In this strain, the multicopy plasmid pSK 1002 bearing an $u m u C /$ lacZ gene fusion product was introduced into Salmonella typhimurium TA1535, and the umu operon was genetically regulated by the SOS genes recA and $\operatorname{lexA}$. The detailed test procedure was described previously by Hu et al. (2007). In this assay, 4-nitroquinoline oxide (4NQO) was used as the positive reference and DMSO as the negative control. The genotoxicity was standarlized to the equivalence to 4-NQO (g 4-NQO/L).

\section{Results and discussion}

\subsection{Effect of ozonation on the formation potentials of typical DBPs}

Figure 2 shows the effects of ozonation dose on the formation potentials of THMs and HAAs. The dominant THM was $\mathrm{CHCl}_{3}$, and the dominant HAAs were DCAA and TCAA before ozonation. Ozonation resulted in an increase in the formation potentials of all the detected DBPs except for $\mathrm{CHCl}_{3}$. At a chlorine dosage of $5 \mathrm{mg} / \mathrm{L}, \mathrm{CHCl}_{3}$ decreased from 51.2 to $37.1 \mu \mathrm{g} / \mathrm{L}$ with an ozone dose increasing from 0 to $10 \mathrm{mg} / \mathrm{L}$, while the total brominated 

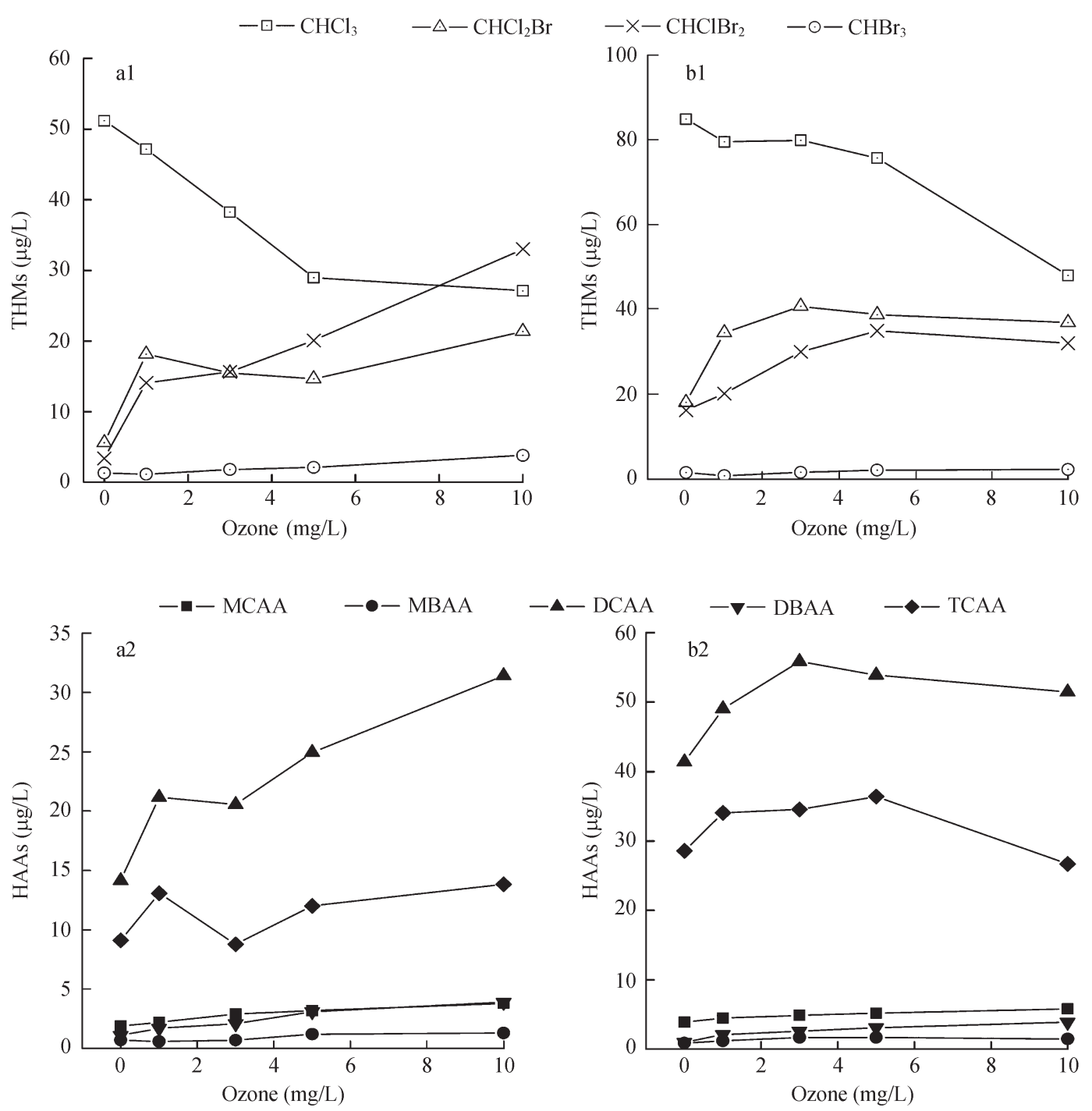

Fig. 2 Effect of ozonation dosage on formation potentials of THMs and HAAs. Chlorine: (a) $5 \mathrm{mg} / \mathrm{L}$; (b) $10 \mathrm{mg} / \mathrm{L}$.

THMs increased from 10.3 to $58.2 \mu \mathrm{g} / \mathrm{L}$, which was mainly contributed by gains of $\mathrm{CHCl}_{2} \mathrm{Br}$ and $\mathrm{CHClBr}_{2}$. Table 1 presents fraction variations of brominated THMs and HAAs as well as DXAAs. Ozonation apparently enhanced the formation of brominated THMs and HAAs. It is generally agreed that DXAA and the brominated HAAs create greater public health concerns (Bull and Angelo, 1995; Diehl et al., 2000). THMs speciation gradually shifts from chlorinated species to mixed bromochloro species with increasing ozone concentration, while only a slight increase of $\mathrm{CHBr}_{3}$ was detected. The increase of brominated HAAs was less significant than that of THMs. The patterns of

Table 1 Fractions of brominated disinfection byproducts (DBPs) and dihaloacetic acid (DXAA)

\begin{tabular}{lllllll}
\hline & $\begin{array}{l}\text { Chlorine } \\
(\mathrm{mg} / \mathrm{L})\end{array}$ & \multicolumn{5}{c}{ Ozone (mg/L) } \\
\cline { 3 - 7 } & 5 & 17 & 41 & 46 & 56 & 61 \\
\hline Brominated THMs & 5 & 7 & 7 & 9 & 11 & 11 \\
Brominated HAAs & 5 & 60 & 63 & 71 & 68 & 70 \\
DXAA & 5 & 30 & 41 & 48 & 50 & 56 \\
Brominated THMs & 10 & 2 & 3 & 5 & 5 & 7 \\
Brominated HAAs & 10 & 59 & 56 & 62 & 63 & 67 \\
DXAA & 10 & & & & & \\
\hline
\end{tabular}

the DBPs formation were different in two applied chlorine dosages. At a low chlorine dose $(5 \mathrm{mg} / \mathrm{L})$, the three brominated THMs and five detected HAAs increased with increasing ozone concentration. However, as the chlorine dosage was $10 \mathrm{mg} / \mathrm{L}$, two bromochlorined THMs and two dominant HAAs, DCAA and TCAA, increased firstly and then decreased, while $\mathrm{CHBr}_{3}, \mathrm{MBAA}$ and TBAA slightly increased with the increase of ozone dose.

Hypobromite could be formed during free chlorination in the presence of bromide ions (Von Gunten and Hoigné, 1996), which is the reason why brominated DBPs could be formed during chlorination. Bromide in water is readily incorporated into HAAs in the form of organically bound bromine during chlorination (Qi et al., 2004). On the other hand, it is well known that bromide could be rapidly oxidized to hypobromite by ozonation (Urs von Gunten, 2003). Although the hypobromite concentrations were not monitored, it is speculated that hypobromite might be formed during ozonation since the bromide concentration is as high as $0.7 \mathrm{mg} / \mathrm{L}$. Previous studies indicate that the reactions of organic compounds with $\mathrm{HBrO} / \mathrm{BrO}^{-}$are faster than those with $\mathrm{HClO} / \mathrm{ClO}^{-}$(Symons et al., 1996). It is reasonable that the brominated DBPs increased with 


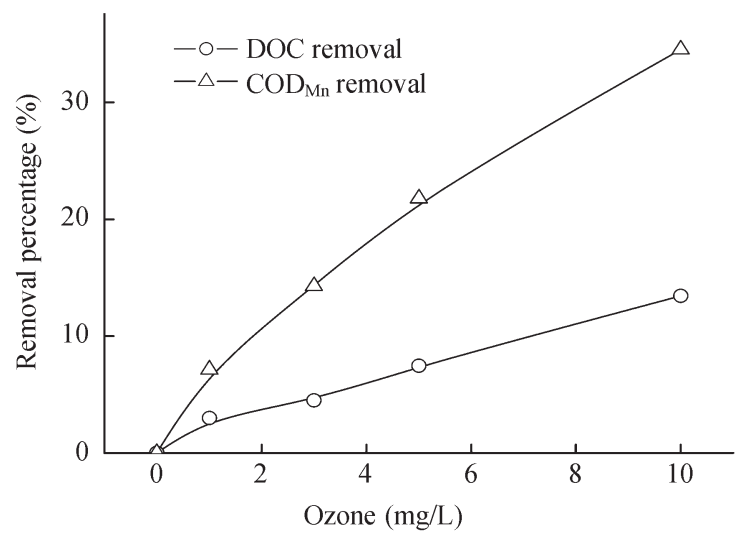

Fig. 3 DOC and $\mathrm{COD}_{\mathrm{Mn}}$ removal during ozonation.

the increase of ozone dose.

The tertiary effluent contains a relatively high concentration of organic compounds. The removals of $\mathrm{COD}_{\mathrm{Mn}}$ and DOC during ozonation are shown in Fig. 3. Along with the ozonation dose increasing from 1 to $10 \mathrm{mg} / \mathrm{L}$, the $\mathrm{COD}_{\mathrm{Mn}}$ removal steadily increased from $7 \%$ to $35 \%$, and a relatively low DOC removal was observed, indicating that ozone has effectively removed reductive compounds from the effluent. The decreased levels of reductive compounds in the ozonated effluents might have led to the reservation of more free chlorine, which could be used for the production of DBPs. According to Cowman and Singer (1996), further halogenation of DCAA to form TCAA occurs only if excessive free chlorine is available. Therefore, the increasing trend of TCAA with increasing ozone dose might be related with the increased level of residual chlorine. On the other hand, ozonation might have transformed aquatic organics into some more active molecules, thereby leading to the increase of some THMs and HAAs.

\subsection{Changes of genotoxicity during the ozonation and chlorination}

The genotoxicity, which was standardized to an equivalent 4-NQO concentration, was determined for the treated samples by the umu assay. As shown in Fig. 4, ozonation at $1 \mathrm{mg} \mathrm{O} 3 / \mathrm{L}$ reduced the genotoxicity from 7.0 to $4.2 \mu \mathrm{g} 4$ -

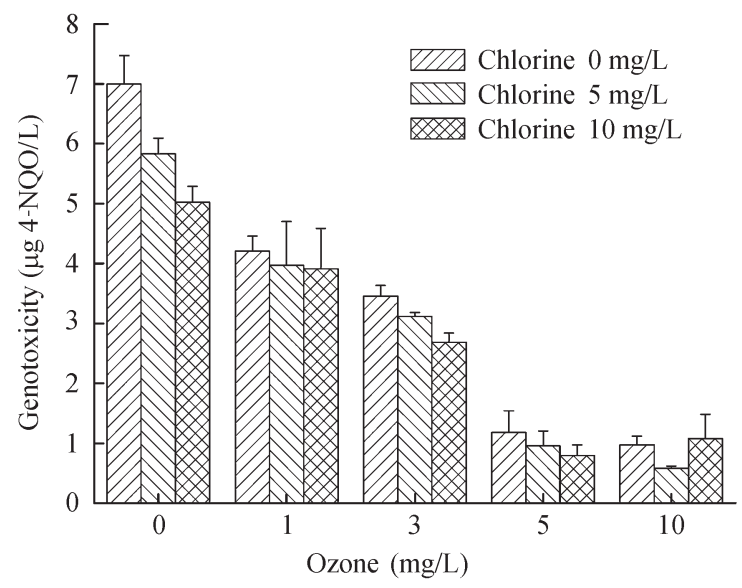

Fig. 4 Genotoxicity changes during the ozonation and post chlorination.
NQO/L, and further decrease of genotoxicity was observed with ozone dose increased. When the ozone dose was increased to $5 \mathrm{mg} / \mathrm{L}$, the genotoxicity decreased to a level as low as the negative control. It is clear that ozonation was very effective in removing the genotoxicity from water. The genotoxicity of samples after chlorination decreased, even ozone enhance the formation of DPBs. The genotoxicity removals were $17 \%$ and $28 \%$ at a chlorine dose of 5 and $10 \mathrm{mg} / \mathrm{L}$, respectively, without ozonation, although marked production of THMs and HAAs was detected. It is possible that the chlorinated/brominated DBPs only made limited contribution to the genotoxicity.

SUVA (UV absorbance divided by DOC concentration) was a parameter indicating the quantity of unsaturated bonds and aromatic organic compound present in organic matter (Goel et al., 1995). Hence the SUVA is helpful to understand the characteristics of organic genotoxic precursors. SUVA removal steadily increased with the increase of ozone dose in the investigated range. As shown in Fig. 5 , the decrease of SUVA correlated well with the removal of genotoxicity during the oxdiation. Hence SUVA could possibly be used as a surrogate indicator for the removal of genotoxicity during ozonation.

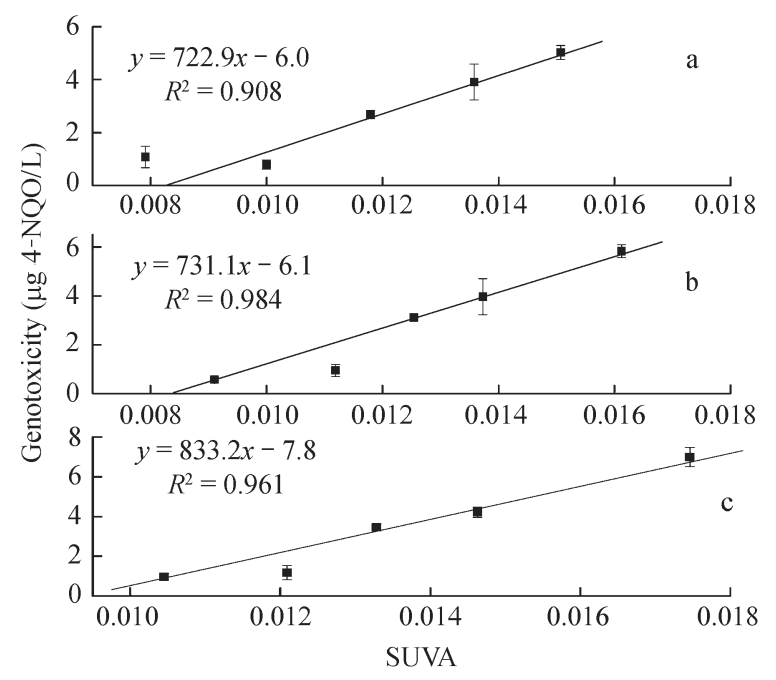

Fig. 5 Relationship between genotoxicity and SUVA during the oxidation. Chlorine: (a) 0; (b) $5 \mathrm{mg} / \mathrm{L}$; (c) $10 \mathrm{mg} / \mathrm{L}$.

\section{Conclusions}

Ozonation of tertiary effluent enhanced the formation of typical chlorination DBPs, and favored the shift of DBPs from chlorinated species to brominated ones. The promotion of brominated THMs formation induced by ozonation was more significant than that of brominated HAAs. However, the genotoxic effects before and after chlorination decreased with the increase of ozone dose. When chlorine dosage was $5 \mathrm{mg} / \mathrm{L}$ the genotoxicity removal level was as low as control. Decrease of SUVA correlated well with the genotoxicity removal during the pre-ozonation, thus SUVA could possibly used as a surrogate indicator for the removal of genotoxicity during ozonation. 


\section{Acknowledgments}

This work was supported by the National Natural Sciences Foundation of China (No. 50525824), the Tianjin Special Innovation Fund (No. 06FZZDSH00900, TJZX1-YW03), and the National Water Project (No. 2008ZX07314-003).

\section{References}

Bull R J, De Angelo A B, 1995. Carcinogenic properties of brominated haloacetates - disinfection byproducts in drinking water: critical issues in health effects. Research International Life Sciences Institute. Washington, DC.

Chang C N, Ma Y S, Zing F F, 2002. Reducing the formation of disinfection by-products by pre-ozonation. Chemosphere, 46: $21-30$.

Cowman G A, Singer P C, 1996. Effect of bromide ion on haloacetic acid speciation resulting from chlorination and chloramination of aquatic humic substances. Environmental Science and Technology, 30: 16-24.

Diehl A C, Speitel G E J, Symons J M, Krasner S W, Hwang C J, Barrett S E, 2000. DBP formation during chloramination. Journal of the American Water Works Association, 92: 7690.

Goel S H, Raymond M, Bouwer E J, 1995. Biodegradation of NOM: effect of NOM source and ozone dose. Journal of the American Water Works Association, 85: 90-105.

Guay C, Rodriguez M, Sérodes J, 2005. Using ozonation and chloramination to reduce the formation of trihalomethanes and haloacetic acids in drinking water. Desalination, 176: 229-240.

Hu J Y, Wang W F, Zhu Z, Chang H, Pan F, Lin B, 2007. Quantitative structure-activity relationship model for prediction of genotoxic potential for quinolone antibacterials.
Environmental Science and Technology, 41: 4806-4812.

Nissinen T K, Miettinen I T, Martikainen P J, Vartiainen T, 2002. Disinfection by-products in Finnish drinking waters. Chemosphere, 48: 9-20.

Qi Y, Shang C, Lo I M C, 2004. Formation of haloacetic acids during monochloramination. Water Research, 38: 23752383.

Singer P C, 1994. Control of disinfection byproducts in drinking water. Journal of Environmental Engineering, 120: 727744.

Symons J M, Krasner S W, Sclimenti M J, Simms L A, Sorensen Jr H W et al., 1996. Influence of bromide ion on trihalomethane and haloacetic formation. In: Disinfection by-Products in Water Treatment: the Chemistry of their Formation and Control (Minear R A, Amy G L, eds.). Florida: Lewis Publishers, 92-130.

Takahara H, Nakayama S, Tsuno H, 2006. Application of ozone to municipal sewage treatment. International Conference Ozone and UV Preceedings. 17-23.

USEPA, 1995. Determination of chlorination disinfection byproducts and chlorinated solvents in drinking water by liquid-liquid extraction and gaschromatography with electron-capture detection, Method 551.1.

USEPA, 2003. Determination of haloacetic acids and dalapon in drinking water by liquid-liquid microextraction derivatization, and gas chromatography with electron capture detection. Method 552.3.

Von Gunten U, Hoigné J, 1996. Ozone of bromide-containing waters: bromate formation through ozone and hydroxyl radicals. In: Disinfection by-Products in Water Treatment: the Chemistry of their Formation and Control (Minear R A, Amy G L, eds.). Florida: Lewis Publishers. 187-206.

Von Gunten U, 2003. Ozonation of drinking water: Part II. Disinfection and by-product formation in presence of bromide, iodide or chlorine. Water Research, 37: 1469-1487. 